\title{
What Can Multiwave Studies Teach Us About Disaster Research: An Analysis of Low-Income Hurricane Katrina Survivors
}

\author{
Gillian Green, Sarah R. Lowe, and Jean E. Rhodes \\ Department of Psychology, Boston, Massachusetts USA
}

\begin{abstract}
Previous research on natural disasters has been limited by a lack of predisaster data and statistical analyses that do not adequately predict change in psychological symptoms. In the current study, we addressed these limitations through analysis of 3 waves of data from a longitudinal investigation of 313 low-income, African American mothers who were exposed to Hurricane Katrina. Although postdisaster cross-sectional estimates of the impact of traumatic stress exposure and postdisaster social support on postdisaster psychological distress were somewhat inflated, the general trends persisted when controlling for predisaster data $(B=0.88$ and -0.33 , vs. $B=0.81$ and -0.27 , respectively). Hierarchical linear modeling of the 3 waves of data revealed that lower predisaster social support was associated with higher psychological distress at the time of the disaster $(\beta=-.16)$, and that higher traumatic stress exposure was associated with greater increases in psychological distress after the storm $(\beta=.86)$. Based on the results, we suggest that the impact of traumatic stress on psychological trajectories cannot be accounted for solely by preexisting risk, and recommend more complex research designs to further illuminate the complex, dynamic relationships between psychological distress, traumatic stress exposure, and social support.
\end{abstract}

On August 29, 2005, Hurricane Katrina struck the Gulf Coast region of the United States, resulting in over 1,800 deaths, and the destruction or severe damage of nearly 250,000 homes (Knabb, Rhome, \& Brown, 2006; U.S. Department of Commerce, 2006). The storm had adverse psychological effects on those exposed, especially low-income individuals, African Americans, and single mothers (e.g., Galea et al., 2007; JonesDeWeever, 2008). These individuals sustained relatively more property damage, the stress of which amplified ongoing struggles with substandard childcare and educational options, racial discrimination, and economic hardship (Spence, Lachlan, \& Griffin, 2007).

Research on the psychological effects of natural disasters on vulnerable populations has been limited by a reliance on postdisaster data. In studies with predisaster data, predisaster symptoms have been shown to be a robust predictor of postdisaster mental health (e.g., Weems et al., 2007). Yet a meta-analysis of 160 disaster studies found that fewer than $5 \%$ studies included predisaster data (Norris et al., 2002). Although studies with solely postdisaster data have shed impor-

\footnotetext{
The study was funded by NIH grant R01HD046162, and the National Science Foundation, the MacArthur Foundation, and the Center for Economic Policy Studies at Princeton University. We thank Thomas Brock, MDRC, Christina Paxson, Elizabeth Fussell, and Mary Waters.

Correspondence concerning this article should be addressed to Jean E. Rhodes, Department of Psychology, University of Massachusetts Boston, 100 Morrissey Blvd., Boston, MA 02125. E-mail: jean.rhodes@umb.edu
}

Copyright (C) 2012 International Society for Traumatic Stress Studies. View this article online at wileyonlinelibrary.com

DOI: $10.1002 /$ jts. 21708 tant light on psychological responses and the roles of disaster exposure and social support in accounting for variation (e.g., Kaniasty \& Norris, 2008; La Greca, Silverman, \& Wasserstein, 1998), lacking controls for predisaster psychological indices, they likely overestimate the impact of predictor variables.

Associations between predisaster indices and disaster exposure could further inflate estimates of the impact of disaster exposure and postdisaster support in predicting postdisaster mental health problems. For example, because those with higher levels of mental health and perceived support can rely on family and friends for shelter, transportation, and other resources, they may face fewer traumatic stressors during the disaster and sustain high levels of postdisaster social and psychological functioning (e.g., Lowe, Chan, \& Rhodes, 2010). By contrast, those who suffer from mental health and social difficulties may have less energy, capacity to plan, and fewer resources on which to draw to escape the disaster.

Studies with predisaster data may help address these limitations, providing better estimates of whether psychological symptoms increase from pre- to postdisaster. They can also assess whether those with higher predisaster distress faced more disaster exposure, and whether exposure and postdisaster support predict postdisaster mental health, controlling for predisaster indices. Although regression analyses controlling for predisaster mental health, however, can provide a sense of how factors contribute to changes in mental health, prediction of residual variation is not equivalent to predicting change. For example, with just two waves of data, it is impossible to determine whether the impact of disaster on psychological distress 
went above and beyond changes that would have been expected with the passage of time (Singer \& Willet, 2003).

Three waves of data permit the use of hierarchical linear modeling (HLM), through which psychological distress trajectories can be examined both in relation to time and disaster occurrence (Raudenbusch \& Bryk, 2002). Within each wave of data collection, there is variation in when participants are assessed, with assessments taking place weeks or even months apart. Longitudinal postdisaster research (e.g., La Greca et al., 1998) has demonstrated that psychological symptoms tend to be elevated in the aftermath of disaster, but then decrease to more normative levels. Without taking variation in timing of assessment into account, analyses may obscure the impact of disasters on trajectories of mental health (King et al., 2006). By entering time and disaster occurrence independently and simultaneously, we assessed the unique impact of each in shaping psychological distress trajectories.

Additionally, HLM permits exploration of the complex relationships among social support, traumatic stress exposure, and psychological symptoms, including associations between predisaster support, traumatic stress exposure, and psychological distress at the time of Hurricane Katrina (i.e., the intercept), as well as postdisaster changes in distress (i.e., the slope).

In the current study, we analyzed data from a longitudinal investigation of low-income, African American mothers exposed to Hurricane Katrina, and who reported on their psychological functioning 2 times prior to the hurricane and again approximately 1 year thereafter. We conducted analyses using one, two, and all three time points to demonstrate the added value of using additional waves of data and statistical methods designed to examine longitudinal patterns of change. We investigated relationships between psychological distress, traumatic stress exposure, and social support through analysis of a longitudinal dataset that included two predisaster waves and one postdisaster wave. We compared analyses with different constellations of data to illustrate some of the limitations in disaster research, the importance of interpreting findings in light of such limitations, and the value that might be added with additional waves of data and more sophisticated methods of analysis.

\section{Method}

\section{Participants and Procedures}

Participants were initially part of a community college educational intervention study in New Orleans in 2004-2005 (Richburg-Hayes et al., 2009). To be eligible for the initial study, students had to be between the ages of 18 and 34 years old, be parents of at least one dependent child under 19, have a household income under $200 \%$ of the federal poverty level, and have a high school diploma or equivalent. At baseline, 1,019 participants (92.5\% female, $84.9 \%$ African American) provided demographic information and completed measures of psychological distress and perceived social support-Time 1 (T1). Hurricane Katrina interrupted a 1-year follow-up-Time 2
(T2) - at which point 492 participants had been reassessed in phone interviews. Trained interviewers conducted T2 assessments, which included the same measures of distress and support. After the hurricane, $402(81.7 \%)$ of the 492 participants were located and reassessed-Time 3 (T3). The T3 surveys were administered by telephone and included the measures of support and distress, and questions assessing traumatic stress exposure. Participants provided written consent at $\mathrm{T} 1$, and verbal consent at $\mathrm{T} 2$ and T3. The institutional review boards from MDRC (a social policy research organization) and the principal investigators' universities (Harvard University, Princeton University, and University of Massachusetts Boston) approved the study.

Given previous research in showing associations between gender, ethnicity, and race and postdisaster mental health (e.g., Brewin, Andrews, \& Valentine, 2000), male $(n=16)$, and non-African American $(n=55)$ participants were excluded. Eighteen additional participants $(n=18)$ were dropped due to missing data. Bonferroni-corrected $t$ tests detected no significant differences between retained and dropped participants.

The mean age of the 313 African American women at T1 was $25.41(S D=4.42)$, and their average number of children at T2 was $1.93(S D=1.16)$. Participants' mean predisaster monthly income was $\$ 619.85(S D=\$ 652.50$, Range: $\$ 3,000)$, and participants reported working an average of 21.78 hours per week $(S D=19.25$, Range: $0-80)$. The majority of participants $(71.9 \%)$ reported receiving governmental benefits; $65.0 \%$ received food stamps, $5.9 \%$ cash assistance or welfare, $17.6 \%$ supplemental security income (SSI), and $1.0 \%$ unemployment. All of the participants reported that their homes were in areas affected by Hurricane Katrina, and nearly half (48.9\%) reported living in areas affected by Hurricane Rita.

\section{Measures}

Psychological distress. Psychological distress was assessed using the K6 scale, which screens for anxiety and mood disorders (Kessler et al., 2002), and has been used in previous research on disaster survivors (e.g., Galea et al., 2007). It includes six items (e.g., "During the past 30 days, about how often did you feel so depressed that nothing could cheer you up?"), with five response options ranging from none of the time to all the time. Scale scores range from 0 to 24 , and scale scores of 0-7 are indicative of probable absence of mental illness, 8-12, probable mild or moderate mental illness, and 13 and above, probable serious mental illness (Kessler et al., 2003); for these data at $\mathrm{T} 1 \alpha=.73, \mathrm{~T} 2 \alpha=.70$, and $\mathrm{T} 3 \alpha=.80$.

Traumatic stress exposure. Participants indicated whether they experienced any of the following as a result of the disasters: (a) lacked knowledge about the safety of their child or children after Katrina (22.4\%), (b) lacked knowledge about the safety of their child or children after Rita (5.4\%), (c) lacked knowledge about the safety of other family members after Katrina (72.2\%), (d) lacked knowledge about the safety 
of other family members after Rita (30.2\%), (e) were separated from their child or children (16.3\%), (f) experienced the death of a close friend or loved one $(28.7 \%)$, and $(\mathrm{g})$ experienced the death or loss of a family pet (14.2\%). These items were selected from a larger scale jointly designed by The Washington Post, the Kaiser Family Foundation, and the Harvard School of Public Health (Brodie, Weltzien, Altman, Blendon, \& Benson, 2006) based on previous research identifying concerns about children and family members, bereavement, and pet loss as key postdisaster stressors in predicting psychological outcomes (e.g., Brewin et al., 2000; Hunt, Al-Awadi, \& Johnson, 2008; Lowe et al., 2010). Scale scores were computed as the total sum of stressors endorsed $(\mathrm{KR}-20=.55)$.

Perceived social support. Perceived social support was assessed using eight items (e.g., "There are people I know will help me if I really need it") from the Social Provisions Scale (Cutrona \& Russell, 1987). Items were rated using a 4-point Likert-type scale (strongly disagree to strongly agree); for these data at $\mathrm{T} 1 \alpha=.76, \mathrm{~T} 2 \alpha=.83, \mathrm{~T} 3 \alpha=.81$.

Time. Timing relative to the onset of Hurricane Katrina was included in the three-wave analysis. Although Hurricane Katrina hit the New Orleans area on August 29, 2005, August 23, 2005 was set as the "zero-point" because disaster-associated disruptions were likely occurring prior to the hurricane's landfall. In supplemental analysis, August 29, 2005 was used and the pattern of results remained unchanged. On average, T1 assessments took place 508.50 days prior to the hurricane (range: 958-256 days prior), T2 104.23 days prior (range: 259-0 days prior), and T3 367.63 days after (range: $266-570$ days after).

Disaster occurrence. A dummy code for disaster occurrence was included in the three-wave analysis. Psychological distress scores were coded as 0 if they were gathered predisaster (i.e., prior to August 23, 2005; T1 and T2 assessments), and 1 if they were gathered postdisaster (i.e., after August 23, 2005; $\mathrm{T} 3$ assessments).

\section{Data Analysis}

Using postdisaster data only (T3), we computed mean psychological distress scores and frequencies of psychological distress scores falling into probable absence of mental illness probable mild or moderate mental illness (MMI), and probable severe mental illness (SMI) classifications. These variables were compared to those of normative samples and other samples of those exposed to Hurricane Katrina. A regression model with traumatic stress and T3 support predicting T3 distress was subsequently tested. In the results, unstandardized coefficients and standard errors are provided.

With two waves of data (T2 and T3), we first documented rates of probable absence of mental illness, probable MMI, and probable SMI in the year prior to Hurricane Katrina (i.e., T2). A paired-samples $t$ test was then computed to assess changes in psychological distress from T2 to T3. Next, we conducted a hierarchical regression model predicting T3 distress, with T2 distress entered in Step 1, T2 support in Step 2, T3 support in Step 3, and traumatic stress in Step 4.

Finally, with all three waves of data, we tested a series of HLMs to assess whether the impact of disaster occurrence went beyond the changes in distress that would be expected over time, and to investigate the contributions of predisaster support and traumatic stress in shaping distress trajectories. Comparison of base models investigated whether the disaster occurrence impacted psychological distress trajectories over and above the passage of time. We first tested models including time and disaster occurrence only, and then a model including both simultaneously. Models were compared with chi-square tests, with significant values indicating an improvement of model fit. Additionally, in the model including both time and disaster occurrence, we assessed whether each remained a significant predictor of variation in distress. These comparisons informed the decision of which base model to use for the predictive models. Predictor variables were added sequentially based on previous research and theory. First, T2 support was added as a predictor of the intercept (Model A), and then as a predictor of the slope (Model B). Next, traumatic stress was added as a predictor of the slope (Model C) and of the intercept (Model D). Significant terms from each model were retained in subsequent models.

\section{Results}

A correlation matrix of all variables included in the study, along with descriptive data, is shown in Table 1. In addition, a summary of the analyses under the different constellations of data, as well as the conclusions drawn about pre- to postdisaster changes of psychological distress, and the roles of social support and traumatic stress exposure is provided in Table 2.

\section{Postdisaster Data Only (T3)}

Mean T3 psychological distress was $6.72(S D=5.28)$, in the probable absence of mental illness range. The majority of participants $(62.1 \%)$ had distress scores indicative of probable absence of mental illness, $23.9 \%$ probable MMI, and $14.0 \%$ probable SMI. The cutoff for SMI on the K6 was selected to identify the 90 to $99^{\text {th }}$ percentile range of the population distribution: A maximum of $10 \%$ of participants in a normative sample would be expected to have SMI (Kessler et al., 2002). Therefore, the levels of distress in the sample were elevated compared to normative samples. Furthermore, they were elevated compared to others exposed to Hurricane Katrina. For example, in a large study of adults who resided in areas exposed to Hurricane Katrina, $11.3 \%$ had psychological distress scores in the SMI range at 5-7 months postdisaster (Galea et al., 2007).

In the regression model, higher traumatic stress and lower T3 support were associated with significantly higher T3 distress $(B=0.88, S E=0.20, p<.001$ and $B=-0.33, S E=0.08$, 
Table 1

Correlation Matrix of Variables in the Study

\begin{tabular}{|c|c|c|c|c|c|c|c|}
\hline Variable & $M$ & $S D$ & 1 & 2 & 3 & 4 & 5 \\
\hline 1. T1 Distress & 4.80 & 3.99 & - & & & & \\
\hline 2. T2 Distress & 5.44 & 4.10 & $.36^{* * *}$ & - & & & \\
\hline 3. T3 Distress & 6.72 & 5.28 & $.31^{* * *}$ & $.37^{* * *}$ & - & & \\
\hline 4. T2 Support & 18.36 & 3.80 & -.09 & $-.29^{* * *}$ & $-.12^{*}$ & - & \\
\hline 5. T3 Support & 17.44 & 3.84 & $-.12^{*}$ & -.10 & $-.26^{* * *}$ & $.33^{* * *}$ & - \\
\hline 6. Traumatic Stress & 2.16 & 1.48 & .02 & .07 & $.29^{* * *}$ & -.11 & $-.12^{*}$ \\
\hline
\end{tabular}

Note. $N=313$. Time 1 (T1) was conducted an average of 508.50 days prior to the hurricane (range: 958-256 days prior); Time 2 (T2) was conducted an average of 104.23 days prior (range: 259-0 days prior); Time 3 (T3) was conducted an average of 367.63 days after (range: 266-570 days after). Traumatic stress was assessed at $\mathrm{T} 3$.

${ }^{*} p<.05 .{ }^{* * *} p<.001$.

$p<.001$, respectively), and explained $13.0 \%$ of the variance in T3 distress, $R^{2}=.13, F(2,289)=20.27, p<.001$.

\section{Pre- and Postdisaster (T2 and T3)}

At T2, 76.6\% of participants had psychological distress scores suggestive of probable absence of mental illness, $17.3 \%$ probable MMI, and 6.1\% probable SMI. A paired-samples $t$ test found that distress significantly increased from $\mathrm{T} 2$ to $\mathrm{T} 3, t(309)=$ $-4.01, p<.001$.

The T2 and T3 variables were then entered into a hierarchical regression model predicting T3 distress (Table 3). In Step 1, higher T2 distress was significantly associated with higher T3 distress. In Step 2, T2 support was not a significant unique predictor of T3 distress. In Step 3, higher T3 support was significantly associated with higher T3 distress. Lastly, in Step 4, higher traumatic stress was associated with higher T3 distress. In the final model, T2 distress, T3 support, and traumatic stress exposure were significant predictors of T3 distress, whereas
T2 support was not. Twenty-four percent of the variance in T3 distress was explained. Notably, with only T3 data, the postdisaster variables (T3 support and traumatic stress) accounted for $13.0 \%$ of the variance in $\mathrm{T} 3$ distress, whereas controlling for predisaster variables, the proportion of variance accounted for by these variables was reduced to $9.7 \%$.

\section{All Waves of Data (T1-T3)}

Base Model 1: Time Only. Average distress at 0 days was estimated at $5.73(S E=0.21)$, with significant variation around this estimate, $\chi^{2}(236)=710.58, p<.001$. The passage of time in days significantly predicted increases in distress, $\beta=.002, t(298)=5.82, p<.001$; each day following August $23^{\text {rd }}$ was associated with a .002 increase in distress, such that 377 days postdisaster (the average date of the T3 assessment), distress was estimated at 6.65. There was significant variability in how participants' distress scores changed over time, $\chi^{2}(230)=327.23, p<.001$.

Table 2

Summary of Analytic Approaches and Conclusions for Disaster Dataset Including Support, Distress Symptoms, and Traumatic Stress

\begin{tabular}{|c|c|c|c|}
\hline Topic & Post (T3) only & Pre- (T2), post- (T3) & Pre- (T1, T2), post- (T3) \\
\hline Analyses & Descriptive; MR & Paired $t$ test; stepwise MR & HLM \\
\hline$\Delta$ in $\mathrm{Sx}$ & None & Increased $\mathrm{T} 2$ to $\mathrm{T} 3$ & $\begin{array}{l}\text { Occurrence predicted } \Delta \\
\text { Time did not predict } \Delta\end{array}$ \\
\hline $\begin{array}{l}\text { Relationship Supp } \\
\text { and Sx }\end{array}$ & Neg & $\begin{array}{l}\text { T3 Supp neg T3 Sx with T2 } \\
\text { indices in model } \\
\text { No T2 Supp with T3 Sx }\end{array}$ & $\begin{array}{l}\text { T2 support neg with } \mathrm{T} 1 / \mathrm{T} 2 \mathrm{Sx} \\
\mathrm{T} 2 \text { supp with } \mathrm{T} 1 / \mathrm{T} 2 \text { to } \mathrm{T} 3 \Delta \text { in } \mathrm{Sx}\end{array}$ \\
\hline $\begin{array}{l}\text { Relationship TS } \\
\text { and Sx }\end{array}$ & TS pos with T3 Sx & $\begin{array}{l}\text { TS pos T3 Sx with T2 indices } \\
\text { in model }\end{array}$ & $\begin{array}{l}\text { TS pos with increases in Sx from } \\
\text { T1/T2 to T3 } \\
\text { Alone, TS pos T1/T2 Sx }\end{array}$ \\
\hline $\begin{array}{l}\% \text { variance } \\
\text { explained }\end{array}$ & 13.0 of $\mathrm{T} 3 \mathrm{Sx}$ & 24.0 of $\mathrm{T} 3 \mathrm{Sx}$ & $\begin{array}{l}11.2 \text { of } \mathrm{T} 1 / \mathrm{T} 2 \mathrm{Sx} ; 24.0 \text { of } \mathrm{Sx} \Delta \\
\mathrm{T} 1 / \mathrm{T} 2 \text { to } \mathrm{T} 3\end{array}$ \\
\hline
\end{tabular}

Note. Time 1 (T1) was conducted an average of 508.50 days prior to the hurricane (range: 958-256 days prior); Time 2 (T2) was conducted an average of 104.23 days prior (range: 259-0 days prior); Time 3 (T3) was conducted an average of 367.63 days after (range: 266-570 days after). Traumatic stress (TS) was assessed at T3. For HLM analysis, distress scores were coded as 0 if gathered predisaster (T1/T2) and 1 if gathered postdisaster (T3). MR = multiple regression; HLM = hierarchical linear model; $\Delta=$ change; $\mathrm{Sx}=$ psychological distress; $\mathrm{Supp}=$ support; Neg = negative association; Pos = positive association. 
Table 3

Results of Regression Model Predicting T3 Distress (T2 and T3 Data)

\begin{tabular}{lllr}
\hline Variable & $B$ & $S E$ & $\beta$ \\
\hline Step 1: $R^{2}=.14$ & & & \\
$\quad$ Constant & $3.91^{* * *}$ & 0.46 & \\
T2 Distress & $0.46^{* * *}$ & 0.07 & .38 \\
Step 2: $R^{2}=.14, R^{2} \Delta<.01$ & & & \\
Constant & $4.92^{* *}$ & 1.62 & \\
T2 Distress & $0.45^{* * *}$ & 0.07 & .37 \\
T2 Support & -0.05 & 0.08 & -.04 \\
Step 3: $R^{2}=.18, R^{2} \Delta=.04^{* * *}$ & & & \\
Constant & $8.03^{* * *}$ & 1.8 & \\
T2 Distress & $0.45^{* * *}$ & 0.07 & .37 \\
T2 Support & 0.06 & 0.08 & .05 \\
T3 Support & $-0.30^{* * *}$ & 0.08 & -.22 \\
Step 4. $R^{2}=.24, R^{2} \Delta=.05^{* * *}$ & & & \\
Constant & $5.58^{* *}$ & 1.82 & \\
T2 Distress & $0.43^{* * *}$ & 0.07 & .36 \\
T2 Support & 0.08 & 0.08 & .06 \\
T3 Support & $-0.27^{* *}$ & 0.08 & -.20 \\
Traumatic stress & $0.81^{* * *}$ & 0.18 & .24 \\
\hline
\end{tabular}

Note. $N=313$. Time 2 (T2) was conducted an average of 104.23 days prior (range: 259-0 days prior); Time 3 (T3) was conducted an average of 367.63 days after (range: 266-570 days after). Traumatic stress was assessed at T3.

${ }^{*} p<.05 .{ }^{* *} p<.01 .{ }^{* * *} p<.001$.

Base Model 2: Disaster Occurrence Only. Predisaster distress was estimated at $4.91(S E=0.20)$, with significant variation among participants, $\chi^{2}(235)=434.17, p<.001$. Disaster occurrence was significantly associated with an average increase of $1.75(S E=0.29)$ in distress, $t(298)=5.98, p<$ .001 , with significant variation in individuals' trajectories, $\chi^{2}$ $(235)=343.94, p<.001$.

Base Model 3: Disaster Occurrence and Time. A final base model was tested including both time and disaster occurrence. In this model, disaster occurrence remained significant, $\beta(298)=1.11, p=.04$, whereas time did not, $\beta(760)=.001$, $p=.17$. In addition, the final base model did not significantly improve model fit compared to disaster occurrence only model, $\chi^{2}(1)=1.88, p=.17$. Given that the significance of the disaster occurrence parameter was over and above the time parameter, we proceeded with the base model including disaster occurrence only (Base Model 2).

Predictive Models. Through predictive models, the relationship between T2 support and traumatic stress exposure on distress at the time of disaster (i.e., distress when disaster occurrence $=0$, the intercept term), as well as changes in distress thereafter (i.e., the slope term), was explored. The results of the predictive models, labeled Models A-D, are listed in Table 4.
In predictive Model $\mathrm{A}, \mathrm{T} 2$ support significantly and negatively predicted predisaster distress, $\beta(297)=-.18, p<.01$. In predictive Model B, T2 support did not significantly predict change in distress associated with disaster occurrence, $\beta(297)$ $=-.01, p=.91$, and was therefore excluded from subsequent predictive models. Traumatic stress exposure significantly and positively predicted increases in psychological distress, $\beta(297)=.89, p<.001$ predicting Model C. In Model D, traumatic stress exposure was not a significant predictor of the intercept. In supplementary analyses, however, the relationship between traumatic stress and the intercept was tested alone, and higher traumatic stress was significantly associated with higher predisaster distress, $\beta(296)=.28, p=.03$.

The final model, Model D, included T2 support as a predictor of predisaster distress (the intercept), and traumatic stress exposure as a predictor of change in distress from the pre- to postdisaster (the slope). Model D explained $11.2 \%$ of the variation in predisaster distress and $24.0 \%$ of the change in distress from pre- to postdisaster.

\section{Discussion}

We conducted a series of analyses using various configurations of data to assess the limits to cross-sectional and preand postdesigns, and to demonstrate the added value of having additional waves of data.

In the cross-sectional analyses, participants' postdisaster distress was elevated relative to normative and other Hurricane Katrina samples, and higher postdisaster distress was significantly related to higher traumatic stress and lower postdisaster support. Given that the sample of low-income women, however, was at higher risk of psychological distress even prior to the disaster (Belle \& Doucet, 2003), postdisaster elevations in distress might have been due in part to preexisting vulnerability. Likewise, without accounting for predisaster psychological distress, the estimates of the impact of traumatic stress and support on postdisaster distress were likely inflated.

With one wave of predisaster data added, we found that the sample had higher levels of psychological distress than normative samples, even prior to disaster. Despite this preexisting vulnerability, participants' distress significantly increased from pre- to postdisaster. Therefore, the conclusion that was reached solely with postdisaster data, i.e., that the hurricane was associated with increased psychological distress, would have been accurate, although inflated.

In a hierarchical regression analysis, controlling for predisaster psychological distress and support, traumatic stress and postdisaster support remained significant, although the effects were attenuated, whereas predisaster support was not a significant predictor of postdisaster distress. These results suggest that, although estimates of the effects of traumatic stress exposure and postdisaster support are inflated using solely postdisaster data, they would likely persist if predisaster indices were included. 
Table 4

Results of Predictive HLM Models

\begin{tabular}{|c|c|c|}
\hline Variable & Coefficient & $S E$ \\
\hline \multicolumn{3}{|c|}{ Base Model 2 (Disaster occurrence only) } \\
\hline \multicolumn{3}{|l|}{ Intercept } \\
\hline Constant & $4.91^{* * *}$ & 0.21 \\
\hline \multicolumn{3}{|l|}{ Slope } \\
\hline Constant & $1.75^{* * *}$ & 0.29 \\
\hline \multicolumn{3}{|l|}{ Model A } \\
\hline \multicolumn{3}{|l|}{ Intercept } \\
\hline Constant & $4.93^{* * *}$ & 0.20 \\
\hline T2 Support & $-0.18^{* * *}$ & 0.05 \\
\hline \multicolumn{3}{|l|}{ Slope } \\
\hline Constant & $1.73^{* * *}$ & 0.29 \\
\hline \multicolumn{3}{|l|}{ Model B } \\
\hline \multicolumn{3}{|l|}{ Intercept } \\
\hline Constant & $4.92^{* * *}$ & 0.20 \\
\hline T2 Support & $-0.17^{* * *}$ & 0.05 \\
\hline \multicolumn{3}{|l|}{ Slope } \\
\hline Constant & $1.73^{* * *}$ & 0.29 \\
\hline T2 Support & -0.01 & 0.08 \\
\hline \multicolumn{3}{|l|}{ Model C } \\
\hline \multicolumn{3}{|l|}{ Intercept } \\
\hline Constant & $4.94^{* * *}$ & 0.20 \\
\hline T2 Support & $-0.17^{* * *}$ & 0.05 \\
\hline \multicolumn{3}{|l|}{ Slope } \\
\hline Constant & -0.18 & 0.47 \\
\hline Traumatic Stress & $0.89^{* * *}$ & 0.18 \\
\hline \multicolumn{3}{|l|}{ Model D } \\
\hline \multicolumn{3}{|l|}{ Intercept } \\
\hline Constant & $4.82^{* * *}$ & 0.36 \\
\hline T2 Support & $-0.16^{* *}$ & 0.05 \\
\hline Traumatic Stress & -0.06 & 0.14 \\
\hline \multicolumn{3}{|l|}{ Slope } \\
\hline Constant & -0.12 & 0.50 \\
\hline Traumatic Stress & $0.86^{* * *}$ & 0.19 \\
\hline
\end{tabular}

Note. $N=313$. Time 2 (T2) was conducted an average of 104.23 days predisaster (range: 259-0 days prior). Distress scores were coded as 0 if gathered predisaster and 1 if gathered postdisaster. Predictive models assessed whether predisaster support and traumatic stress exposure were significant associated with predisaster distress (the intercept terms) and changes in distress from preto postdisaster (the slope terms). Coefficients listed are unstandardized values. The deviances of each model, with number of parameters in parenthesis, were as follows. Base Model 2: 4356.84 (6); Model A: 4344.99 (7); Model B: 4344.97 (8); Model C: 4320.90 (8); and Model D: 4320.73 (9). HLM = Hierarchical linear model.

${ }^{*} p<.05 .{ }^{* *} p<.01 .{ }^{* * *} p<.001$.

Despite the insights drawn from the comparison of results with pre- and postdisaster data, limitations remained. First, although we documented increased levels of psychological distress, it was impossible to determine whether the impact of disaster on psychological distress went above and beyond changes that would have been expected with the passage of time. Fur- thermore, not all of those exposed are equally vulnerable to disaster stress exposure; for example, those with psychological difficulties and lacking social support might be at increased vulnerability to hurricane exposure.

We addressed these limitations by adding an additional wave of predisaster data. Using HLM, we found that disaster occurrence impacted psychological distress trajectories above and beyond the passage of time. Additionally, although lower predisaster support was significantly associated with higher distress prior to disaster occurrence, it did not predict changes in distress in the aftermath of the disaster. Again, these results added nuance to the findings that emerged with fewer waves. From the pre- and postanalysis, one might assume that predisaster support is not related to postdisaster psychological distress, and that postdisaster support is more pertinent to postdisaster mental health outcomes. Through HLM, we found that low predisaster support could still place an individual at risk for postdisaster distress through its significant association with predisaster psychological distress.

Our results also shed light on associations between psychological distress and traumatic stress exposure. Participants reporting more traumatic stressors showed greater increases in psychological distress. The results also suggested a relationship between higher predisaster distress and greater exposure to disaster-related traumatic stressors; that is, individuals reporting more psychological distress prior to disaster may be at greater risk for traumatic stress during the disaster and its immediate aftermath. This relationship did not stand, however, when traumatic stress was included as a predictor of change in distress. The HLM results contrast with the pre- and postregression analysis, which detected a significant, positive relationship between traumatic stress and distress, both pre- and postdisaster, but could not separately and simultaneously assess relationships between predisaster distress and change in distress.

In sum, through a series of analyses, we demonstrated that interpretations of disaster effects could be shaped by available datasets. Several conclusions can be drawn. First, although results from postdisaster studies overestimate the impact of traumatic stress exposure on mental health, the general trends in the data should be seen as accurate, albeit inflated. Second, although some individuals might be at increased risk of traumatic stress exposure due to their psychological symptoms, the impact of traumatic stress on psychological trajectories cannot be accounted for solely by preexisting risk.

\section{Limitations}

Although there are advantages to having predisaster data, and particularly multiple predisaster waves, there are limitations when following participants of a study not originally intended to study the effects of disasters. As stated previously, the participants in the current study were African American women who were initially part of a community college intervention study for low-income parents. Although the homogeneous nature of the sample allowed us to focus on the effects of disaster on 
a vulnerable population, it limited the generalizability of the findings. Furthermore, the community college student sample may have had systematically differed in their levels of distress, support, and traumatic stress exposure from other low-income African American mothers in the New Orleans area. Follow-up studies of more representative samples or other populations are needed. Additionally, the unique features of Hurricane Katrina, including a foreseeable failure of levees and delayed responses to low-income residents and people of color (Lavelle \& Feagin, 2006; Park \& Miller, 2006), should be taken into account when interpreting the findings.

Access to additional waves of data would have permitted a more nuanced understanding of the complicated and dynamic relationships among psychological distress, traumatic stress exposure, and social support. For example, if we had an additional wave of data, we would have been able to test for nonlinear models of change. This is particularly important given that the HLM model with time assumed a constant rate of change in postdisaster distress. It is more likely that participants initially experienced an increase in symptoms, followed by a decrease. This pattern, however, could not be assessed with only one wave of postdisaster data. With even more data, researchers could understand how natural disasters alter psychological distress trajectories, for example, testing models allowing for multiple intercepts and slopes.

The measures included also lacked specificity. For example, the psychological measure, the K6 Scale, assessed nonspecific psychological distress. An advantage of using this measure is that it has been included in previous studies of Hurricane Katrina (e.g., Galea et al., 2007), permitting comparison of distress levels. On the other hand, we were unable to explore trajectories of specific disorders commonly found in the aftermath of disasters, including posttraumatic stress and depression. An analysis of the trajectories of these disorders, and their associations with perceived social support and traumatic stress exposure, would be informative for interventions postdisaster. Moreover, because the K6 is a screening scale, it is inherently less precise than clinical interviews, which could attenuate the associations found in the study (Galea et al., 2007).

In addition, the measure of perceived social support did not distinguish between different forms of support (e.g., emotional, informational, tangible), limiting our ability to assess the associations between predisaster support and trajectories of psychological distress. In addition, like psychological distress, perceptions of support change in the aftermath of disasters (e.g., Kaniasty \& Norris, 1993; Lowe et al., 2010). It is likely that changes in support relate to changes in distress, which could be explored with additional waves of data.

In our postdisaster assessment, the traumatic stress variable did not encompass all aspects of exposure to the hurricane, but rather focused largely on immediate concerns (e.g., children's safety) and losses (e.g., bereavement) in the aftermath of disasters that previous research has found to be predictive of psychological responses (e.g., Brewin et al., 2000). Other forms of exposure common to disaster literature, such as property damage, financial loss, and displacement, were not included, nor were direct threats to participants' lives. The results therefore may not align with those of other studies that include different aspects of traumatic stress, and the findings should be interpreted with caution.

More generally, all data were self-report and future researchers should include other measures, including more objective measures of psychological functioning, social support, and traumatic stress exposure. Inclusion of variables that might account for additional variance in postdisaster psychological distress, such as access to material resources (e.g., employment, income) is also recommended.

\section{Conclusion}

Despite these limitations, this study has implications for the interpretation of findings from previous studies on the psychological effects of natural disasters. Although researchers using cross-sectional postdisaster and pre- and postdesigns should use caution in drawing conclusions from their data, our analyses provided evidence that the general trends detected in these studies hold in longitudinal and more complex research designs. In addition to the methods typically employed in disaster research, investigators should aim to gather data that includes multiple pre- and postdisaster data points. Such research could enrich our understanding of the ways in which individuals, families, and communities are affected by disasters over time.

\section{References}

Belle, D., \& Doucet, J. (2003). Poverty, inequality and discrimination as sources of depression among women. Psychology of Women Quarterly, 27, 101-113. doi:10.1111/1471-6402.00090

Brewin, C. R., Andrews B., \& Valentine J. D. (2000). Meta-analysis of risk factors for posttraumatic stress disorder in trauma-exposed adults. Journal of Consulting \& Clinical Psychology, 68, 748-766. doi:10.1037/0022006X.68.5.748

Brodie, M., Weltzien, E., Altman, D., Blendon, R. J., \& Benson, J. M. (2006). Experiences of Hurricane Katrina evacuees in Houston shelters: Implications for future planning. American Journal of Public Health, 96, 1402-1408. doi:10.2105/AJPH.2005.084475

Cutrona, C. E., \& Russell, D. (1987). The provisions of social relationships and adaptation to stress. In W. H. Jones \& D. Perlman (Eds.), Advances in personal relationships (Vol. 1, pp. 37-67). Greenwich, CT: JAI Press.

Galea, S., Brewin, C. R., Gruber, M., Jones, R. T., King, D. W., King, L. A., ... Kessler, R. C. (2007). Exposure to hurricane-related stressors and mental illness after Hurricane Katrina. Archives of General Psychiatry, 64, 1427-1434. doi:10.1001/archpsyc.64.12.1427

Hunt, M., Al-Awadi, H., \& Johnson, M. (2008). Psychological sequelae of pet loss following Hurricane Katrina. Anthrozoös, 21, 109-121. doi:10.2752/175303708X305765

Jones-DeWeever, A. (2008). Women in the wake of the storm: Examining the post-Katrina realities of the women of New Orleans and the Gulf Coast. Washington, DC: Institute for Women's Policy Research.

Kaniasty, K., \& Norris, F. H. (1993). A test of the social support deterioration model in the context of natural disaster. Journal of Personality and Social Psychology, 64, 395-408. doi:10.1037//0022-3514.64.3.395

Kaniasty, K., \& Norris, F. H. (2008). Longitudinal linkages between perceived social support and posttraumatic stress symptoms: Sequential roles of social 
causation and social selection. Journal of Traumatic Stress, 21, 274-281. doi: $10.1002 /$ jts.20334

Kessler, R. C., Andrews, G., Colpe, L. J., Hiripi, E., Mroczek, D. K., Normand, S.-L.T., . . \& Zaslavsky, A. M. (2002). Short screening scales to monitor population prevalances and trends in nonspecific psychological distress. Psychological Medicine, 32, 959-976. doi:10.1017/S0033291702006074

Kessler, R.C., Barker, P. R., Colpe, L. J., Epstein, J. F., Groerer, J. C., Hiripi, E., ... \& Zaslavsky, A. M. (2003). Screening for serious mental illness in the general population. Archives of General Psychiatry, 60, 184-189. doi:10.1001/archpsyc.60.2.184

King, D. W., King, L. A., McArdel, J. J., Grimm, K., Jones, R. T., \& Ollendick, T. H. (2006). Characterizing time in longitudinal trauma research. Journal of Traumatic Stress, 19, 205-215. doi:10.1002/jts.20112

Knabb, R. D., Rhome, J. R., \& Brown, D. P. (2006). Tropical cyclone report: Hurricane Katrina. National Hurricane Center. Retrieved from http://nhc.noaa.gov/pdf/TCR-AL122005_Katrina.pdf

La Greca, A. M., Silverman, W. K., \& Wasserstein, S. B. (1998). Children's predisaster functioning as a predictor of posttraumatic stress following Hurricane Andrew. Journal of Consulting and Clinical Psychology, 66, 883-892. doi:10.1037//0022-006X.66.6.883

Lavelle, K., \& Feagin, J. R. (2006). Hurricane Katrina: The race and class debate. Monthly Review. Retrieved from http://www.monthlyreview .org/0706lavelle.htm

Lowe, S. R., Chan, C. S., \& Rhodes, J. E. (2010). Pre-hurricane perceived social support protects against psychological distress: A longitudinal analysis of low-income mothers. Journal of Consulting and Clinical Psychology, 78, 551-560. doi:10.1037/a0018317
Norris, F., Friedman, M., Watson, P., Byrne, C., Diaz, E., \& Kaniasty, K. (2002). 60,000 disaster victims speak. Part I: An empirical review of the empirical literature, 1981-2001. Psychiatry, 65, 207-239. doi:10.1521/psyc.65.3.207.20173

Park, Y., \& Miller, J. (2006). The social ecology of Hurricane Katrina: Rewriting the discourse of 'natural' disasters. Smith College Studies in Social Work, 76, 9-24. doi:10.1300/J497v76n03_02

Raudenbush, S. W., \& Bryk, A. S. (2002). Hierarchicical linear models: Applications and data analysis methods (2nd ed.). Thousand Oaks, CA: Sage.

Richburg-Hayes, L., Brock, T., LeBlanc, A., Paxson, C., Rouse, C. E., \& Barrow, L. (2009). Rewarding persistence: Effects of a performance-based scholarship program for low-income parents. New York: MDRC.

Singer, J. D., \& Willet, J. B. (2003). Applied longitudinal analysis: Modeling change and even occurrence. New York: Oxford University Press.

Spence, P. R., Lachlan, K. A., \& Griffin, D. R. (2007). Crisis communication, race, and natural disasters. Journal of Black Studies, 37, 539-554. doi:10.1177/0021934706296192

U.S. Department of Commerce. (2006). Gulf coast recovery: 17 months after the hurricanes. Washington, DC: Economics and Statistics Administration. Retrieved from www.economics.noaa.gov/library/documents/ economics_for_coastal_marine_management/gulf-coast-recovery-esa.doc

Weems, C. F., Pina, A. A., Costa, N. M., Watts, S. E., Taylor, L. K., \& Cannon, M. F. (2007). Predisaster trait anxiety and negative affect predict posttraumatic stress in youths after Hurricane Katrina. Journal of Consulting and Clinical Psychology, 75, 154-159. doi:10.1037/0022-006X.75.1 .154 